\title{
Tolerance of Tomato Cultivars and Selected Germplasm to Heat Stress
}

\author{
Aref A. Abdul-Baki \\ Vegetable Laboratory, Plant Sciences Institute, Agricultural Research Service, U.S. Department of \\ Agriculture, Beltsville, MD 20705 \\ Additional index words. Lycopersicon esculentum, high temperature, flowering, fruit set, yield, seed development
}

\begin{abstract}
Nine heat-tolerant tomato [Lycopersicon esculentum (Mill.)] breeding lines, four heat-tolerant cultivars, and four heat-sensitive cultivars were evaluated in the greenhouse under high temperature (39C day/28C night) and in the field. Criteria for heat tolerance included flowering, fruit set, yield, fruit quality, and seed production. Under high-temperature conditions, the group of heat-tolerant lines, the heat-tolerant cultivars, and the heat-sensitive cultivars produced, respectively, the following per plant: flowers, 186, 94, and 55; fruit set $70 \%, 52 \%$, and $30 \%$; yield, 410, 173, and $11 \mathrm{~g}$; and normal mature fruit, $72 \%, 37 \%$, and $7 \%$. Yields of heat-tolerant lines under high temperature in the greenhouse ranged from $118 \%$ to $31 \%$ of their respective yields in the field. Yields of heat-tolerant cultivars were $62 \%$ of those in the field. In contrast, yields of heat-sensitive cultivars under high temperature were $<1 \%$ of their respective yields in the field. High temperature induced flower abscission, reduced fruit set and yield, and increased the incidence of abnormalities. Major fruit abnormalities with high temperatures included cracks, blossomed rot, watery tissue, and small, immature fruits. Production of viable seeds under the high-temperature regime was severely reduced or totally inhibited regardless of the heat-tolerance level exhibited by the line or cultivar. The failure of heat-sensitive and most heat-tolerant cultivars or lines to produce viable seeds under such a high temperature suggests that a lower level of heat stress than that applied in these experiments could allow the production of enough seeds to test the relationship between heat tolerance in a genotype and its ability to produce viable seeds under high temperature. The results indicate that certain lines have high tolerance to heat and, therefore, could provide valuable sources of plant material for physiological studies to establish the physiological and molecular bases of heat tolerance. Some of the heat-tolerant lines might also serve as excellent germplasm sources in breeding heat-tolerant tomato cultivars.
\end{abstract}

Lack of tolerance to high temperature in most tomato cultivars presents a major limitation for growing an economic crop in regions where the temperature during part of the growing season, even for short durations, reaches $38 \mathrm{C}$ or higher (Johnson and Hall, 1953; Stevens and Rudich, 1987). Progress in developing heat-tolerant cultivars has been hindered by the complexity of the trait and its low heritability values (Scott et al., 1986; Villareal and Lai, 1979). In a genetic analysis of parental lines and their hybrid progenies, Villareal and Lai (1979) reported heritability values from $5 \%$ to $19 \%$. They concluded that the major portion of observable variability among parental lines and their hybrid progenies was caused by environmental variables among which the most important was the relative humidity (Abdalla and Verkerk, 1968; Scott et al., 1986).

Identification of heat tolerance in tomatoes has been accomplished by evaluating them for flowering and fruit set, because these two processes are sensitive to heat and relate directly to yield (Berry and Uddin, 1988; El Ahmadi and Stevens, 1979; Hanna and Hernandez, 1982; Rudich et al., 1977). However, the impact of high temperatures on the plant is not limited to flowering and fruit set. High temperatures also affect the subsequent development and maturity of the fruit and thereby further reduce the crop (Charles and Harris, 1972; Hanna and Hernandez, 1982). Major nonreproductive processes, such as photosynthetic efficiency (Bar-Tsur et al., 1985), assimilate translocation (Tanaka et al., 1974; Went and Hull, 1949), mesophyll resistance (Stevens and Rudich, 1987), and disorganization of cellular membranes (Chen et al., 1982) have been observed. The last has been suggested as a possible screening method for heat tolerance by measuring the leakage of electro-

Received for publication 9 May 1990. The cost of publishing this paper was defrayed in part by the payment of page charges. Under postal regulations, this paper therefore must be hereby marked advertisement solely to indicate this fact. lytes from leaves that had been subjected to heat stress (Shen and $\mathrm{Li}, 1982$ ). The present study was undertaken to 1) evaluate the performance of heat-tolerant lines and cultivars and heatsensitive cultivars when grown under high temperatures; and 2) investigate the relationship between heat tolerance in a genotype and the ability of the genotype to produce viable seeds under high temperature. Should such a relationship exist, production of viable seed under high temperature may be used as both a screening method and a mechanism for selecting for heat tolerance. Criteria used for establishing the level of heat tolerance were flowering, fruit set, yield, fruit quality, and production of viable seeds.

\section{Materials and Methods}

Seed source and identity. The study included nine lines and eight commercial cultivars (Table 1). Lines designated 1-9 were made available by the Asian Vegetable Research and Development Center (AVRDC), Taiwan; these (designated heat-tolerant lines) were genetically selected for heat tolerance at AVRDC. Cultivars 10-13 (heat-tolerant cultivars) were made available by J. W. Scott, Univ. of Florida; these were 'Fresh Market 9', 'Saladette', 'Processor 40', and 'Solar Set'. Cultivars 14-17 were purchased from commercial sources and are typical of commonly used commercial cultivars lacking tolerance to heat (heat-sensitive cultivars). These, 'Campbell 28', 'Duke', 'FloraDade', and 'Long Keeper', served as controls.

High-temperature plantings. Two high-temperature experiments, each consisting of five plants of each line or cultivar, were carried out in the greenhouse during Spring and Summer 1989. Seeds were planted on 6 and 21 Apr. in flats containing perlite and were kept at a $28 / 20 \mathrm{C} \pm 2 \mathrm{C}$ day/night cycle. At the four-leaf stage, seedlings were transplanted into 4-liter pots containing sterilized soil and were maintained in the greenhouse at a 38-40C/29-31C day/night cycle until all fruits borne on the 
Table 1. Cultivar identification and quality of fruits formed under high temperature.

\begin{tabular}{|c|c|c|c|c|c|c|}
\hline \multirow[b]{2}{*}{ Line/cultivar no. } & \multirow[b]{2}{*}{$\begin{array}{l}\text { Accession no./ } \\
\text { cultivar name }\end{array}$} & \multirow[b]{2}{*}{$\begin{array}{c}\text { Normal fruits } \\
(\%)\end{array}$} & \multicolumn{4}{|c|}{ Abnormal fruits (\%) } \\
\hline & & & Cracked & $\begin{array}{l}\text { Blossom- } \\
\text { end rot }\end{array}$ & Watery & $\begin{array}{c}\text { Small/ } \\
\text { immature }\end{array}$ \\
\hline \multicolumn{7}{|l|}{$\begin{array}{l}\text { Heat-tolerant } \\
\text { lines }\end{array}$} \\
\hline 1 & CL1131-0-043-0-6 & 86 & 0 & 1 & 9 & 4 \\
\hline 2 & CL6058-0-3-10-2-2-2 & 74 & 0 & 10 & 0 & 16 \\
\hline 3 & CLN475BC $\mathrm{F}_{2}-265-4-19$ & 73 & 5 & 0 & 1 & 21 \\
\hline 4 & CLN65-349D $-2-0$ & 67 & 0 & 9 & 0 & 24 \\
\hline 5 & CL5676BC $_{1} \mathrm{~F}_{2}-1-2-2-12$ & 83 & 0 & 3 & 0 & 14 \\
\hline 6 & CL5915406D $-2-2-0-4$ & 58 & 15 & 2 & 20 & 5 \\
\hline 7 & CL5915-93-1-0-C-1 & 71 & 13 & 3 & 0 & 13 \\
\hline 8 & CL1131-0-0-13-0-6 & 86 & 0 & 0 & 0 & 14 \\
\hline 9 & CL5915-153D $4-3-3-0-N S 1$ & 53 & 0 & 18 & 0 & 29 \\
\hline \multicolumn{7}{|l|}{$\begin{array}{l}\text { Heat-tolerant } \\
\text { cultivars }\end{array}$} \\
\hline 10 & Fresh Market 9 & 44 & 9 & 11 & 5 & 31 \\
\hline 11 & Saladette & 56 & -6 & 23 & 5 & 10 \\
\hline 12 & Processor 40 & 40 & 8 & 7 & 3 & 42 \\
\hline 13 & Solar Set & 9 & 49 & 2 & 30 & 10 \\
\hline \multicolumn{7}{|l|}{$\begin{array}{l}\text { Heat-sensitive } \\
\text { cultivars }\end{array}$} \\
\hline 14 & Campbell 28 & 21 & 21 & 21 & 5 & 32 \\
\hline 15 & Duke & 3 & 64 & 19 & 8 & 6 \\
\hline 16 & Flora-Dade & 4 & 33 & 2 & 56 & 5 \\
\hline 17 & Long Keeper & 1 & 99 & 0 & 0 & 0 \\
\hline
\end{tabular}

lowest five inflorescences reached maturity. Water was applied once or twice a day, as needed, to avoid water stress. Ten grams of fertilizer $(10 \mathrm{~N}-10 \mathrm{P}-10 \mathrm{~K})$ was applied to the pot of each plant twice during the growing season. The first application was at initial fruit set, the second 3 weeks later. Lime was also applied twice at a rate of $10 \mathrm{~g} / \mathrm{plant}$ each time. The first application was 1 week after transplanting, and the second, 3 weeks later. Pollination of flowers was performed daily around midday, using a mechanical vibrator. All other operations were typical of practices performed in greenhouse production of tomatoes. The procedures noted will be referred to as "high-temperature conditions."

Field plantings. Two field plantings were made on the farm at the Agricultural Research Center, Beltsville, Md., during Summer 1989. Seeds were germinated in the greenhouse on 6 and 23 Apr. Seedlings were transplanted into the field on 23 May and 2 June, respectively. In each planting, each line or cultivar represented a treatment consisting of 22 plants. Plants were spaced $0.65 \mathrm{~m}$ apart within the row with $1.6 \mathrm{~m}$ between rows, following a randomized complete-block design. All cultural operations were similar to those practiced in commercial field production. These field plantings were originally designed to compare the genotype performance in a relatively warm climate in the field with that under high temperature in the greenhouse. The average maximum temperature in the field during the flowering and fruit-set periods (1 June to 30 July) was 28 and $30 \mathrm{C}$ for June and July, respectively, and the highest temperature for 1 day was $35 \mathrm{C}$. The daytime averages for these 2 months were 28 and $29 \mathrm{C}$, and the nighttime averages were 18 and 19C, respectively. Therefore, the data on field plantings represent a reasonable estimate of field performance of the tested lines and cultivars under commonly encountered conditions and will be referred to as "field conditions."

Flowering fruit set, yield, and fruit quality. The number of flowers per plant was determined on 10 plants (five from each planting) for the greenhouse studies and on eight plants (four from each planting) in the field. AU of the flowers produced by a plant were counted up to the time when all the fruits on the lowest three inflorences reached maturity. Individual inflorescences on each plant were tagged and flower counts were made weekly. Fruit set (percent) and average fruit weight were determined on the lowest three inflorescences of plants in the greenhouse and on the whole plant in the field. Fruit set was considered attained when the diameter of the fruit was $\geq 5 \mathrm{~mm}$. Relative earliness was established on the two field plantings by determining the number of days required from planting until the appearance of one or more fruits of turning ripeness on $10 \%$ of the plants in each genotype. No attempt was made to establish the relative earliness of the genotypes under greenhouse conditions. Yield in the greenhouse and field was determined on the whole plant throughout the growing season. Because of the high incidence of fruit abnormalities under high-temperature conditions in the greenhouse, fruits were harvested at 4-day intervals beginning on 22 June and ending on 3 Aug., when all fruits on the lowest five inflorescences reached the pink stage. They were weighed and evaluated for cracks, blossom-end rot, external watery translucent tissue, and small immature fruit. Harvest in the field extended from 12 July to 28 Sept. to allow enough time for fruits of late-maturing lines and cultivars to ripen. In all cases, only normal fruits were included in the yield data.

Seed production and germination. Seed production was determined on 20 fruits from each line or cultivar grown in the field and all the fruits produced by the 10 plants of each group under greenhouse conditions. The seeds were removed from the fruit at the firm-ripe stage and soaked $1 \mathrm{~h}$ in $5 \% \mathrm{HCl}$ solution at room temperature under gentle stirring. They were then washed, dried, and stored for several weeks at 20C. A standard germination test was done according to the International Rules for Seed Testing (International Seed Testing Assn., 1985), using 400 seeds per test. Because of extremely low seed production by all cultivars under high temperature, the number of seeds 
used in the test included all the seeds formed in the fruits that had developed and matured under high temperature. Furthermore, because of the low germination exhibited by seeds that had developed under high temperature, the number of seeds per fruit was expressed as number of viable seeds that germinated and did not include immature seeds that failed to germinate.

Data reported in this study on flowering, fruit set, yield, fruit quality, and seed production under field and high temperature conditions are the averages of the two plantings.

\section{Results and Discussion}

High temperature and flowering and fruit set. Four of the high-temperature tolerant lines produced more and five lines produced fewer flowers under high-temperature conditions than in the field (Fig. 1A). Although the effect of other environmental factors on flowering cannot be totally excluded, flowering in this group was reduced by $17 \%$ under the high-temperature conditions. Reduction in flowering by high temperature in the high-temperature tolerant cultivars and the high-temperature sensitive cultivars was $38 \%$ and $68 \%$, respectively. Under field conditions, the high-temperature tolerant and the high-temperature sensitive cultivars produced $35 \%$ and $27 \%$ fewer flowers, respectively, than the high-temperature tolerant lines, as compared with $49 \%$ and $70 \%$ reductions under high-temperature conditions. High-temperature tolerant lines and high-temperature tolerant cultivars produced a higher percentage fruit set under high-temperature conditions than in the field (Fig. 1B). The reverse was observed in the high-temperature sensitive cultivars. Under high-temperature conditions, average fruit set in the high-temperature tolerant lines, high-temperature tolerant cultivars, and high-temperature sensitive cultivars was $70 \%, 52 \%$, and $30 \%$ of the flowers formed, respectively. The effect of mechanical pollination applied daily under high-temperature conditions on fruit set could not be determined, since seed production in all tested genotypes was severely reduced or com-
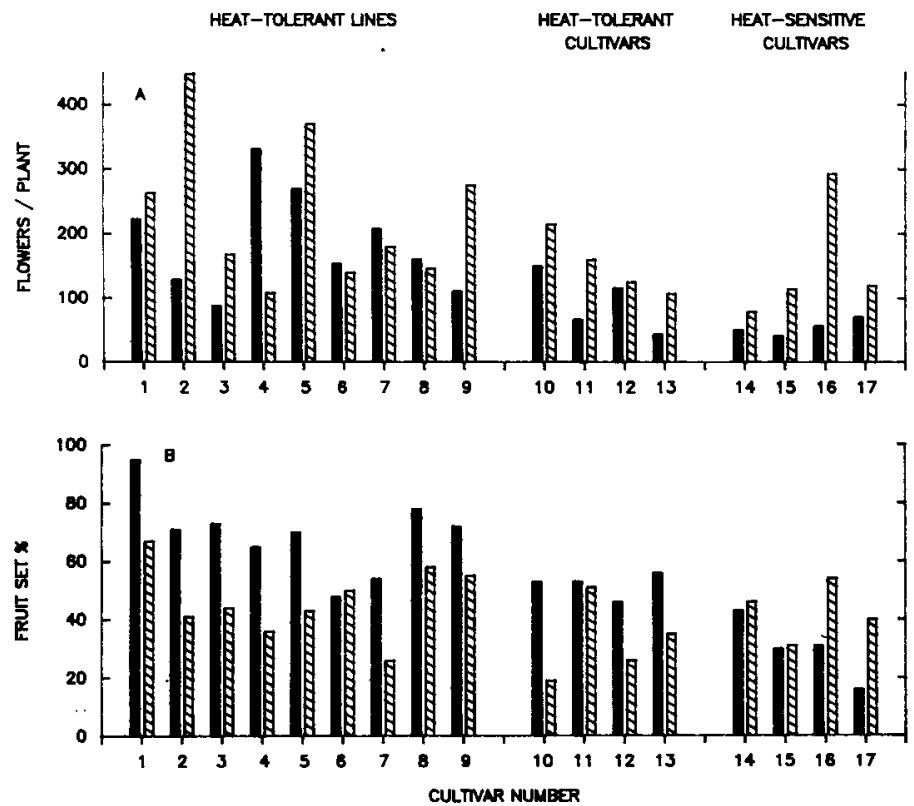

Fig. 1. Flowering (A) and percentage fruit set (B) of heat-tolerant lines (1-9), heat-tolerant cultivars (10-13), and heat-sensitive cultivars (14-17) under high-temperature conditions (solid bars) and in the field (striped bars). Lines and cultivars are identified in Table pletely inhibited under high-temperature conditions regardless of the level of heat tolerance (Fig. 2C). The impairment of seed formation in the fruits under high temperature could, in part, have contributed to the observed reduction in fruit weight under high temperature (Fig. 2B) and, consequently, to the reduction in yield (Fig. 2A).

Effect of high temperature on yield and fruit quality. Under high-temperature conditions, the high-temperature tolerant lines, without exception, outyielded the high-temperature tolerant cultivars (Fig. 2A). The heat-sensitive cultivars did very poorly. The reverse was observed under field conditions where the hightemperature sensitive cultivars outyielded the high-temperature tolerant lines and cultivars. These high-temperature sensitive commercial cultivars appear to have a high yield potential that can be expressed only when high-temperature stress conditions do not prevail. As would be expected, yield under field conditions was lower in the early maturing than in the late-maturing genotypes (Fig. 3), with the exception of genotypes 3, 9, and 12. Early maturing genotypes produce less vigorous vines than late-maturing genotypes. As a result, they generally set fruits earlier and yield less than the vigorous late-maturing genotypes. Furthermore, the relationship of earliness in the field to the response of the genotypes under high-temperature stress was established by running a regression analysis using earliness in the field and percent abnormal fruits under high temperature conditions. Genotypes were arranged relative to one another for
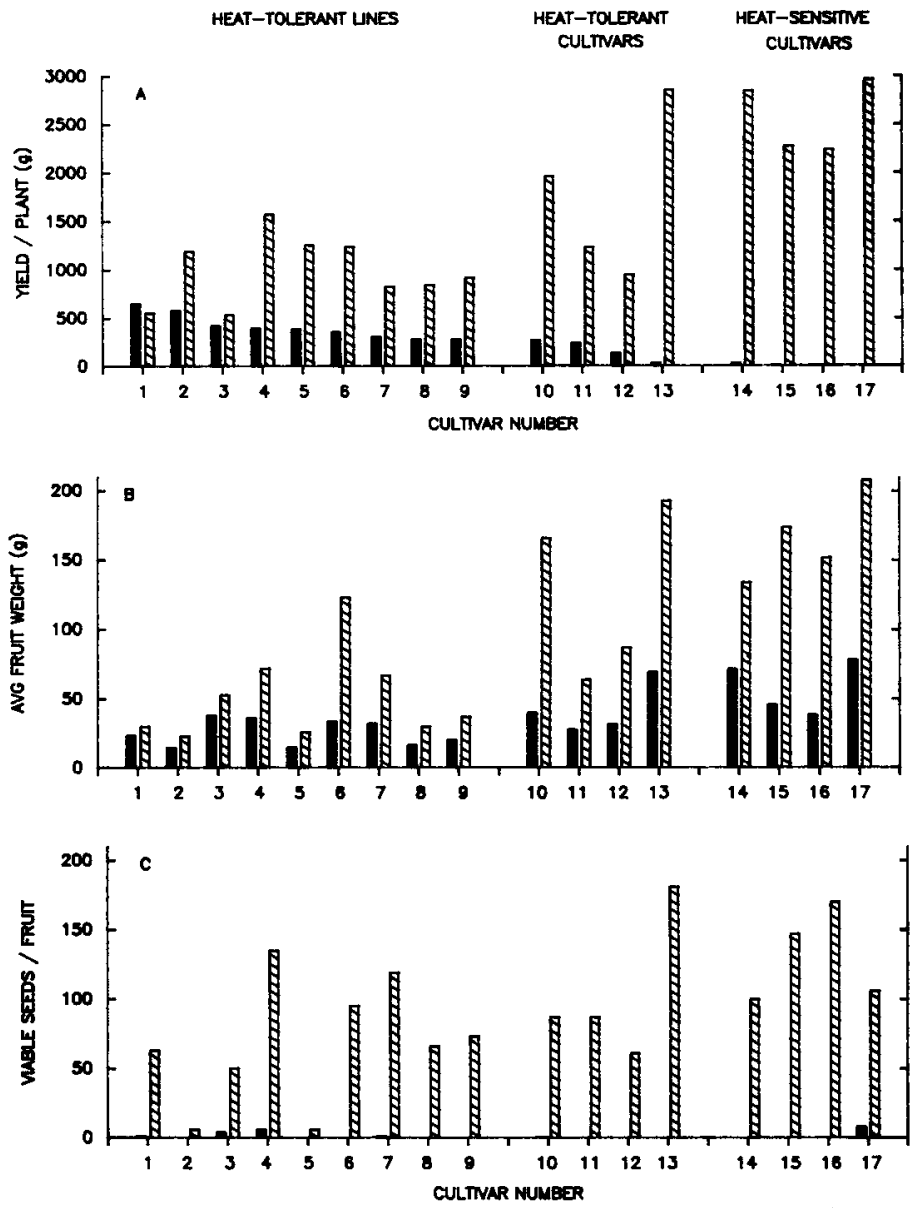

Fig. 2. Yield (A), average fruit weight (B), and viable seeds per fruit (C) of heat-tolerant lines (1-9), heat-tolerant cultivars (10-13), and heat-sensitive cultivars (14-17) under high-temperature conditions (solid bars) and in the field (striped bars). Lines and cultivars are identified in Table 1. 


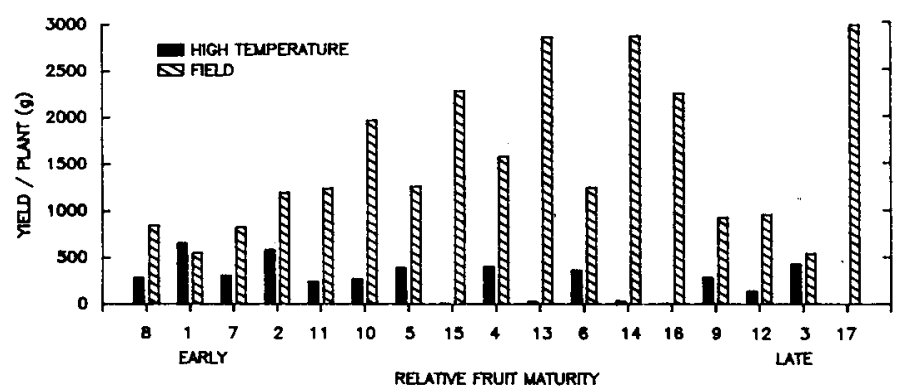

Fig. 3. Relationship of fruit maturity to yield of tomatoes grown under high-temperature conditions and in the field. Numbers on the abscissa refer to lines and cultivars as identified in Table 1. Relative fruit maturity refers to the time from planting to the appearance of the first turning fruit on $10 \%$ of the plants in each genotype under field conditions.

earliness for this analysis, and the regression analysis was run on these ranks. The slope of the regression line $(\mathrm{b}=3.4, P<$ 0.02 ) was significantly higher than zero, indicating that percent abnormalities increased with relative lateness.

Average fruit weight of normal marketable fruits under high temperature in heat-tolerant lines was $=5770$ of that in the field, whereas in both heat-tolerant and heat-sensitive cultivars it declined to 35\% (Fig. 2B). Thus, heat-tolerant lines exhibited a smaller reduction in fruit weight than the other two groups under high temperature. Lowest reduction in fruit weight under high temperature was observed in heat-tolerant line 1 , which also demonstrated the highest fruit set (Fig. 1B).and yield (Fig. 2A) and fewest fruit abnormalities (Table 1) under high temperature. Although reduction in fruit weight might be a function of several factors, such as fruit size and puffiness, it appears from the data that the higher the level of heat tolerance, the lower the reduction in fruit weight under heat-stress conditions.

Fruit abnormalities were rare in the field but occurred frequently in heat-sensitive and, to a lesser extent, in heat-tolerant cultivars grown under high temperature (Table 1). The most common abnormalities in fruits were cracks, blossom-end rot, watery tissue, and small/immature fruits. Abnormal fruits of heat-tolerant lines grown under high temperature ranged from $14 \%$ to $47 \%$ of all fruits that had reached maturity, averaging $\approx 28 \%$. In contrast, abnormal fruits produced by heat-tolerant and heat-sensitive cultivars were $63 \%$ and $93 \%$ of the total fruit, respectively.

Effect of high temperature on development of viable seeds. All lines and cultivars produced viable seeds under field conditions, with the high-temperature tolerant cultivar 13 producing the most, followed by heat-sensitive cultivars 16 and 15 (Fig. $2 \mathrm{C})$. However, high temperatures severely reduced seed set in some genotypes and totally inhibited it in others. In several lines and cultivars, not enough seeds were produced to establish a relationship between the ability of a genotype to produce seeds under high temperature and its tolerance to heat stress. Consequently, the second objective set forth at the start of the experiment was not accomplished. Reductions in seed set by tomatoes grown under high temperatures have been reported (El Ahmadi and Stevens, 1979).

The heat-stress condition under which the greenhouse experiments were conducted induces the synthesis of heat-shock proteins (Neumann et al., 1987; Never and Scharf, 1984). These proteins have been suggested to protect the plant from heat damage. The observed reduction or even total inhibition of seed development under heat stress may suggest that heat-shock proteins have little to do with seed set.
According to the field studies, the heat-tolerant lines had a lower yield potential than the heat-tolerant and the heat-sensitive cultivars. However, under high-temperature conditions, the heattolerant lines outyielded the other two groups of cultivars because high temperature caused only a slight reduction in flowering and no reduction in fruit set in this group. These heattolerant lines offer opportunities as a genetic source of heat tolerance for breeding cultivars adapted to high-temperature stress. They may also be useful in physiological and biochemical studies of the molecular basis of heat tolerance.

\section{Literature Cited}

Abdalla, A. and K. Verkerk. 1968. Growth, flowering, and fruit-set of the tomato at high temperature. Neth. J. Agr. Sci. 16:71-76.

Bar-Tsur, A., J. Rudich, and B. Bravdo. 1985. High temperature effects on $\mathrm{CO}_{2}$ gas exchange in heat-tolerant and sensitive tomatoes. J. Amer. Soc. Hort. Sci. 110:582-586.

Berry, S.Z. and M.R. Uddin. 1988. Effect of high temperature on fruit-set in tomato cultivars and selected germplasm. HortScience 23:606-608.

Charles, W.B. and R.E. Harris. 1972. Tomato fruit-set at high and low temperatures. Can. J. Plant Sci. 52:497-506.

Chen, H., Z.Y. Shen, and P.H. Li. 1982. Adaptability of crop plants to high temperature stress. Crop Sci. 22:719-725.

El Ahmadi, A. and M.A. Stevens. 1979. Reproductive responses of heat-tolerant tomatoes to high temperatures. J. Amer. Soc. Hort. Sci. 104:686-691.

Hanna, H.Y. and T.F. Hernandez. 1982. Response of six tomato genotypes under summer and spring weather conditions in Louisiana. HortScience 17(5):758-769.

International Seed Testing Association. 1985. The germination test. International rules for seed testing. Seed Sci. and Technol. 13:322326.

Johnson, S.P. and W.C. Hall. 1953. Vegetative and fruiting responses of tomatoes to high temperature and light intensity. Bet. Gaz. 114:449460.

Neumann, D., U. Nieden, R. Manteuffel, G. Walter, K. Scharf, and L. Never. 1987. Intracellular localization of heat-shock proteins in tomato cell cultures. European J. Cell Biol. 43:71-81.

Never, L. and K. Scharf. 1984. Synthesis, modification and structural binding of heat-shock proteins in tomato cell cultures. European J. Biochem. 139:303-313.

Rudich, J., E. Zamski, and Y. Regev. 1977. Genotype variation for sensitivity to high temperature in the tomato: Pollination and fruitset. Bet. Gaz. 138:448-452.

Scott, J. W., R.B. Volin, H.H. Bryan, and S.M. Olson. 1986. Use of hybrids to develop heat tolerant tomato cultivars. Proc. Fla. State Hort. Soc. 99:311-315.

Shen, Z. Y., and P.H. Li. 1982. Heat adaptability of the tomato. HortScience 17:924-925.

Stevens, M.A. and J. Rudich. 1987. Genetic potential for overcoming physiological limitations on adaptability, yield, and quality of the tomato. HortScience 13:673-679.

Tanaka, A., K. Fujita, and K. Kikuchi. 1974. Nutrio-physiological studies on the tomato plant: Photosynthetic rates of individual leaves in relation to the dry matter production in plants. Soil. Sci. Plant Nutr. 20:173-183.

Villareal, R.L. and S.H. Lai. 1979. Development of heat tolerant tomato varieties in the tropics. Proc. First Intl. Symp. Trop. Tomatoes. Asian Veg. Res. Dev. Ctr., Shanhua, Taiwan.

Weaver, M.L. and H. Timm. 1989. Screening tomato for high-temperature tolerance through pollen viability tests. HortScience 24:493495.

Went, F.W. and H.M. Hull. 1949. The effect of temperature upon translocation of carbohydrates in the tomato plant. Plant Physiol. 24:505-526. 